\title{
A virtual nursing honor society: Recognition for online academic excellence
}

\author{
Kathleen C. Spadaro, Emily E. Stevens, Michelle Doas, Debra Wolf, J ulie Slade, Diane F. Hunker \\ Department of Nursing, Chatham University, Pittsburgh, PA, USA.
}

Correspondence: Kathleen C. Spadaro. Address: Department of Nursing, Chatham University, Pittsburgh, PA, USA. Email: kspadaro@chatham.edu

Received: December 5, 2013

Accepted: December 15, 2013 Online Published: January 5, 2014

DOI : 10.5430/jnep.v4n3p197

URL: http://dx.doi.org/10.5430/jnep.v4n3p197

\begin{abstract}
The growth of online education has created a challenge to academic institutions, faculty, and professional honor societies with the desire to capture those students who excel in their field and retain institutional affiliation from a distance. A private university nursing program decided to meet this challenge by creating a virtual Nursing Honor Society (vNHS) for academically superior students from their RN-BSN, MSN, and DNP online programs. The process began with a task force of faculty members to develop an infrastructure that would support a student organization within a larger university academic system. This article presents the pre-planning process, the website design, the process of conducting virtual induction ceremonies, and committee structure for virtual events that established the vNHS. Challenges and lessons learned are presented to promote replication in other academic institutions that offer online programming. The vNHS has been beneficial for students and the larger University.
\end{abstract}

\section{Key words}

Virtual honor society, Online education, Academic excellence, Nursing

\section{Introduction}

Membership in an honor society has been a longstanding tradition to acknowledge academic excellence. With the current increase of online education programs in nursing, innovative methods to recognize outstanding student achievement need to be employed. A small, private university in Southwestern Pennsylvania has sought to fulfill this need by creating a virtual Nursing Honor Society (vNHS). This article seeks to share their process as well as provide key points to consider for successful replication and development by other academic institutions.

\section{Background}

Recognition of student excellence is not foreign to higher education institutions in the United States. The oldest known national academic honor society was established in $1776{ }^{[1]}$. Following tradition, today's honor societies are made up of individual college chapters that distinguish and promote academic excellence within a particular discipline ${ }^{[2]}$. Membership to an honor society typically occurs during the undergraduate and graduate years of education. 
The academic environment and depiction of traditional college students are changing. Online programs have grown dramatically over the past several years and so has the number of students enrolled in these programs. Not only have the amount of online programs grown, so has the perceived acceptance of the virtual programs by individuals seeking higher education. Currently 6.7 million students are taking an online course totaling $32 \%$ of all U. S. students ${ }^{[3]}$. In a recent survey by Allen and Seaman (2013), 69\% of academic leaders reported that online learning is a crucial component to their long-term strategy and that enrollment in online programs has reached the highest level in the past 10 years. In the same study, $77 \%$ of those institutions rate learning outcomes in online programs as comparable or superior to those in face-toface settings.

Research indicates there is no significant difference between an online learner compared to an on the ground learner and their achieved learning outcomes ${ }^{[4]}$. Furthermore, research has demonstrated that a "sense of community" can be developed through online learning ${ }^{[5-7]}$, which is not only beneficial to learning but also for the professional role. The growth in online learning and the lack of difference between the two types of students illustrates the need to provide online students the same opportunities as traditional students.

Nursing is one of the fields that utilize online education (defined as structured academic content delivered within a virtual learning management system) to promote continuing education beyond post-licensure training. In the American Association of Colleges of Nursing (AACN) 2013 Annual Report, 484 of 568 (85.2\%) RN-to-Baccalaureate nursing programs were delivered with some amount of online education in their curriculum, with 198 (34.9\%) programs entirely online. In the Master of Science in Nursing (MSN) programs, 318 out of 372 (85.5\%) were delivered online, and in the Doctor of Nursing Practice (DNP) programs, 195 out of 216 (90.3\%), were delivered with some online component, with $19.4 \%$ and $20.4 \%$ fully online respectively ${ }^{[8]}$.

Today, most professional nursing organizations and societies have created virtual websites or community virtual platforms via social media for the purpose of updating their members who are currently practicing nurses. One example is Sigma Theta Tau International (STTI) Nursing Honor Society. They have a chapter titled "Phi Gamma virtual chapter" which was created for nurses practicing in the community who might not have had the opportunity to join a local chapter of Sigma Theta Tau International through a traditional on ground educational institution ${ }^{[9]}$. However, the Phi Gamma chapter does not provide the common shared experience of other Sigma Theta Tau chapters that consist of institutional alumni.

Acknowledging the need for an honor society that recognizes academic excellence among online nursing students and alumni, a small, private university in Southwestern Pennsylvania created a virtual Nursing Honor Society (vNHS). The purpose of the vNHS was to recognize academic performance, provide students and alumni with the opportunity to create a sense of community through their online learning experiences at the same institution, and establish an avenue in which to promote lifelong learning, recognize leadership, share scholarship, provide mentoring, and establish networking.

\section{Development process}

The vNHS was developed to capture qualified individuals from each of the three online post-licensure nursing programs (RN-BSN, MSN, and DNP). These students, enrolled in one of the three nursing programs, consisted of registered nurses residing across the United States. A task force was formed with four volunteer nursing faculty members to spearhead the project.

\section{University approval}

The initial planning meeting occurred in February 2011 and the four volunteers became the president, vice-president, treasurer, and secretary (see Table 1). This founding vNHS board agreed that Sigma Theta Tau International's (STTI) criteria would be used as a reference for establishing a mission statement and membership criteria ${ }^{[10]}$, in hopes for future 
chapter membership. Other key items were identified for development: vNHS by-laws, alumni eligibility, use of the university's learning management system for website design and access, marketing of the vNHS, and member scholarship opportunities. The vNHS board worked with Student Affairs Organization administration at the university to secure official society approval. However, to be recognized as a student organization, it was not permissible to include members who were not alumni or active university students. Although this conflicted with STTI membership guidelines, the board acknowledged the need to adhere to university policy for development purposes. As such, the vNHS was officially accepted as a student organization on April 11, 2011.

Table 1. List of Virtual Nursing Honor Society Officers

\begin{tabular}{|c|c|}
\hline Position Title & Position Description \\
\hline President & $\begin{array}{l}\text { The President serves as the chief representative of the honor society. This position administers society business } \\
\text { and coordinates all Board of Directors meetings. The President can serve as an ex-officio member of } \\
\text { committees, with the exception of the Leadership Succession Committee. It is also the responsibility of the } \\
\text { president to ensure that required reports such as the Annual Report and the Society Fee Verification form are } \\
\text { submitted by their designated due dates. }\end{array}$ \\
\hline Vice President & $\begin{array}{l}\text { The Vice President performs various responsibilities on behalf of the society. This position performs the duties } \\
\text { of the president in the president's absence. The Vice President also facilitates achievement of society goals and } \\
\text { oversees at least two society programs each year. The Vice President often oversees the membership } \\
\text { engagement efforts and frequently chairs or serves on committees as needed }\end{array}$ \\
\hline Treasurer & $\begin{array}{l}\text { The Treasurer is responsible for managing society funds. This includes preparing the annual budget and } \\
\text { developing or maintaining fiscal policies and procedures. The treasurer is required to present financial } \\
\text { information to the Board of Directors at each meeting and works with the President to complete the financial } \\
\text { section of the annual report }\end{array}$ \\
\hline Secretary & $\begin{array}{l}\text { The Secretary is responsible for recording and distributing meetings minutes, along with preparing and } \\
\text { distributing chapter correspondence. Secretaries can chair and/or serve on committees as needed }\end{array}$ \\
\hline Counselor & $\begin{array}{l}\text { The Counselor is responsible for selecting candidates based on membership eligibility criteria determined by } \\
\text { the society constitution and the exception guidelines chosen by the Board Members. The counselor is also } \\
\text { responsible for sending membership invitations and managing the induction process }\end{array}$ \\
\hline Web Editor & $\begin{array}{l}\text { The Web Editor is responsible for maintaining the society's visibility electronically through a web portal that is } \\
\text { accessible by all members within the organization, the institution and the community. The web portal } \\
\text { functionality will support the synchronized and asynchronized communication between various committees } \\
\text { and chapter members. The web portal will also be used for publicizing events and news to chapter members } \\
\text { while hosting virtual gatherings for meetings, inductions, and other events. }\end{array}$ \\
\hline
\end{tabular}

\section{Financial considerations}

A key step in establishing a vNHS was the ability to manage the organization's finances. The university's Business Office created a separate account for the vNHS that was used for all financial transactions, including funding for activities such as the induction ceremony, printing/mailing of member certificates, and creation/distribution of vNHS pins. In addition to collecting and recording of monies, the vNHS treasurer also assumed responsibility for monitoring the balance and working with the Business Office. Funds for the account came directly from student induction fees (\$25) and member renewal fees (\$15). In addition, undergraduate and graduate student organization monies were applied for and provided by the university Student Affairs office.

\section{Web access}

Following the initial development activities, the vNHS board added two additional officers, the Counselor and Web Editor (see Table 1). The development of the vNHS website was crucial since this was the primary avenue for communication between members. The Web Editor assisted and advised the vNHS board with exploring, planning and formalizing a website format and worked to secure a web name, domain and platform. Multiple decisions needed to be made: vNHS website look and logo, information displayed, public or private site, needed functionality (such as active links, video broadcasting, blogging, etc.), and finally level of communication between members via the website (one way or two way). 
In order to create this virtual presence, permission was needed from the university's Web Editor to use the university's webserver to host the vNHS webpage within the university's platform.

\section{I nduction of initial members}

Induction of initial vNHS members captured alumni from one year prior in addition to all current students who met admission criteria for the vNHS. Admission criteria were based on the STTI admission criteria for undergraduate and graduate students. After the board approval of the final list of vNHS candidates, invitation letters from the president and vNHS board were emailed to potential inductees in October 2011.

Due to the geographic spread of candidates, the induction was designed as a virtual ceremony. Applicants interested in joining the vNHS were asked to submit a personal photo to be used in the virtual ceremony. The photos were displayed during the ceremony's PowerPoint presentation (as each applicants name was announced). Table 2 outlines a list of key steps the board had taken to plan the virtual induction ceremony. All vNHS board members, as well as the program coordinators of the three nursing programs, served as presenters during the ceremony. The video, recorded by university students, was saved and uploaded to the webserver and all inductees were invited to view the asynchronous ceremony. The first NHS virtual induction ceremony welcomed 58 inductees who consisted of 35 DNP students, 11 MSN students, and 12 RN-BSN students. Members spanned from 17 different states from Alaska to Florida. All inductees were mailed a vNHS membership certificate and society pin following the ceremony.

Table 2. Key Planning Steps for First Induction Ceremony

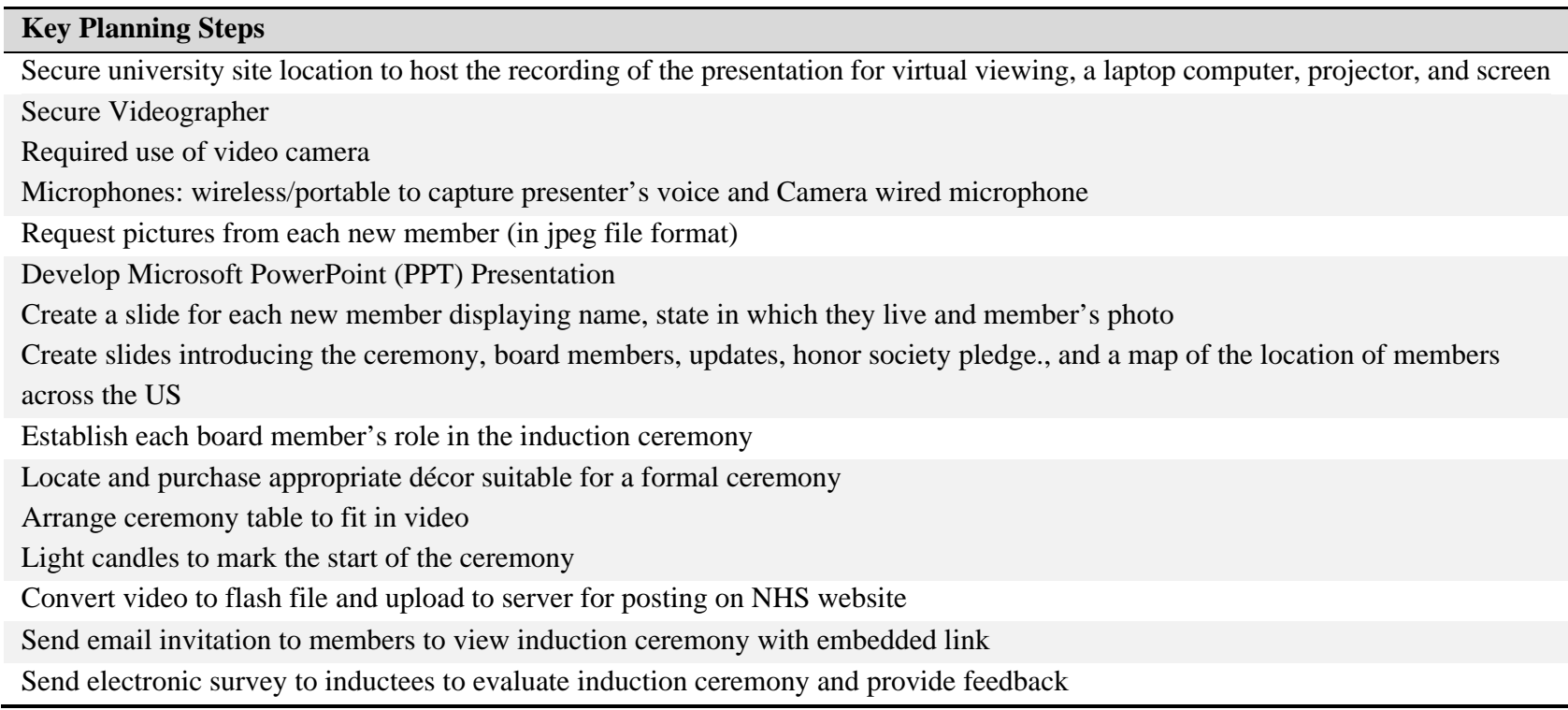

\section{Current development}

After the first induction ceremony, committees other than the governance committee that oversees bylaws and membership were created to further promote the goals of the vNHS. A revised membership application identified membership interest. Although initially five committees had been created, the dilemma of too many groups and too few resources promoted the need for committee restructuring. The goals of those five were merged into two committees. These committees became the Leadership Succession Committee with a focus on identifying leadership activities for members and initiation of officer election ballots, and the Scholarship, Education, and Technology (SET) Committee, which runs educational and scholarship programs, including technology updates, for the vNHS members. Since the committee members were not located in the same geographic areas, committee meetings were held via teleconference calls and follow-up communication via email. Committee membership was voluntary, including the chair positions, and consisted of current students, faculty, board members, and alumni, all vNHS members. 
As a result of the work on the committees, multiple activities were planned, created, and completed since the initial induction ceremony in December 2011. A "Toolkit" was created and linked to the website which offers "How-To" programs on using technology. Three additional virtual induction ceremonies were conducted using the same format as the original ceremony except for the addition of a formal speaker such as the STTI regional chair and distinguished vNHS members. A peer-reviewed, virtual Poster Session took place in January 2013 that showcased scholarship of vNHS members. Members as well as non-members were invited to comment and ask questions, via a blog format, regarding the scholarship presented on the poster. An electronic evaluation was sent using Qualtrics to all members regarding their satisfaction with the poster session, as either a reviewer or a presenter.

Future planned activities include annual virtual poster sessions and a virtual journal club. A website "leadership corner" of various vNHS members who are nurse leaders is also under development. Further plans for the toolkit, "Technology How-To's” will focus on increased understanding of new technologies that may be used by the vNHS student and professional members. In addition, ideas for networking events with other nursing honor societies at other colleges or universities are being considered.

\section{STTI progress}

Following the required waiting period, the vNHS applied for official membership to Sigma Theta Tau International Honor Society for Nursing in February 2013. Official confirmation has been received; the vNHS has been approved and will become a STTI chapter in Spring 2014. Efforts over the past two years have resulted in a highly functional and successful virtual honor society that recognizes academic excellence and promotes scholarship and leadership. The board of officers is optimistic that the future of the vNHS will be productive and eventful.

\section{Discussion}

To date, there are 118 members in the vNHS. Twenty members serve on the three committees and the original board members are still in place, although their terms have been defined and will expire over the next year, staggered to maintain consistency. While it may appear that the development of the vNHS went smoothly, it was the result of much hard work by a handful of founding faculty. Unforeseen challenges were encountered along the way. The challenges can be categorized into five categories: committees, technology, membership, funding, and university.

\section{Challenges}

Committees. The biggest challenge experienced by the Board to date has been the ability to accomplish activities with committee members in various professional roles and various time zones. While faculty and nurses working different shifts are able to meet virtually during the day, most clinicians and administrators are able to teleconference in the evenings. This has resulted in inconsistent participation. To date, the solution has been to rotate meeting times each month to accommodate all members with each meeting having clearly recorded minutes to share with all vNHS members. Another initial challenge was to shift the leadership role in the committees away from the founding vNHS board members and onto newly inducted members. Since the board members were faculty at the university, the student and alumni inductees needed prompting to take on a leadership role. Through open discussion and support, founding board members were able to identify and encourage two strong alumni leaders to take the leadership succession and SET committee chair roles.

Technology. The technology needs were also a major challenge during the development of the vNHS. The biggest technological challenge was where to place the website. For ease of access and cost the initial idea was to place the vNHS website on the learning management system (LMS) used by the university. This level of access would have worked well for the faculty and current student members, but alumni no longer have access to the university LMS. To address this issue, the vNHS used the university's current website platform to host their website. This created additional work in learning 
Contribute, a web development software, and at times delayed additions or revisions to the vNHS website since they had to be approved by the university Web Editor. This caused additional steps in the website development process.

In addition, the virtual induction ceremonies also presented some technological challenges. The goal set by the board members was to have the ceremonies be virtual and asynchronous, yet personal and meaningful for the participants. As a result, decisions for displaying, viewing, and uploading the first virtual induction ceremony had to be made. Easy access via the vNHS was achieved by creating hyperlinks, with clearly marked language guiding individuals on where to click to view the ceremony were created.

Membership. The vNHS also experienced some of the typical challenges faced by most societies - keeping people interested, getting people involved, and having people renew their membership. Without the resources and technology to allow people to renew through an online payment system, the renewal process remains somewhat cumbersome requiring members to print, fill out renewal applications, and mail them in with a check. However, following the STTI chartering, this will no longer be an issue as the STTI has an online payment system for the vNHS members.

Funding. As with any organization, the vNHS encountered some obstacles with funding. The start-up costs involved with the vNHS and the projected costs to maintain the vNHS, especially if the society becomes a STTI chapter, could be considerable. Unrealized future costs associated with becoming a STTI chapter include the formal STTI chapter induction ceremony (once) and the cost of sending one or two members or officers to the STTI Biennial Conference (every two years). Unfortunately, limited funding support from the university only occurred in the first year of existence. Coupled with the challenge of getting current members to renew, the financial account of the vNHS is not as robust as the current board would like. As such, efforts are being made to pursue fund raising activities to sustain the vNHS.

University. The final challenge to be discussed dealt with navigating through the university infrastructure and approval processes. Working within the university system was often times difficult because many of the requirements for new organizations were more relevant to traditional, on-ground, undergraduate students, at this small, private institution. Fortunately, the dean of student services eventually clarified that certain requirements did not relate to the vNHS since the primary focus was on graduate and continuing education students. Furthermore, trying to meet the university requirements in addition to the STTI requirements proved to be difficult and resulted in discrepancies requiring detailed clarification when submitting the application for STTI membership.

\section{Recommendations}

While there were many challenges that needed to be addressed, ultimately the development and implementation of a virtual nursing honor society was a success. Table 3 addresses key points that should be considered when deciding to start a virtual society of any kind. By knowing what you may encounter, and what steps to take, others may also be successful in starting a society aimed at recognizing academic excellence and promoting scholarship and leadership for online students.

Table 3. Lessons for Development of a Virtual Society

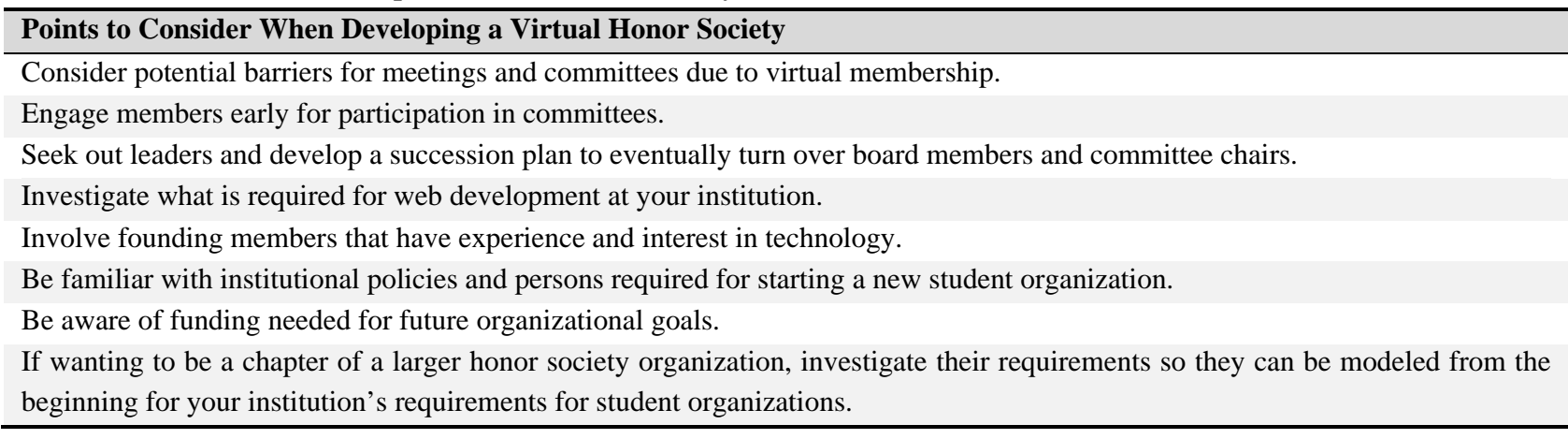




\section{Conclusion}

Recognizing academic excellence is important for any institution yet finding innovative methods may be challenging for online programs. As demonstrated, invested faculty can develop a virtual honor society and induct members interested in furthering their leadership, professionalism, knowledge, and scholarship with their academic peers. Identifying and mitigating challenges before they present may prove to be beneficial. Securing departmental, university, and technological support is key to any successful start-up organization. Once membership goals are met, continued development and participation in activities and events can illuminate the accomplishments of graduates allowing continued recognition of their excellence within the nursing profession.

\section{Competing interests}

The authors declare that they have no competing interests.

\section{Authors' contributions}

The first author drafted the outline of this manuscript and has been responsible for formatting the manuscript and any major revisions along with the second author. Each of the six authors was responsible for a section of the content that the first and second authors then compiled into one manuscript. All authors provided a critical appraisal of the entire manuscript for revisions have provided final approval of this manuscript to be submitted for publication.

\section{Acknowledgements}

The authors wish to acknowledge the faculty, university administration, and the nursing students for supporting our work in developing this vNHS. A special thank you goes to the web director of the university for all of her support, patience, and guidance.

\section{References}

[1] Phi Beta Kappa. The nation's oldest and most widely known academic honor society. http://www.pbk.org/infoview/PBK_InfoView.aspx?t=\&id=8 (2 December 2013, date last accessed).

[2] Association of College Honor Societies. ACHS membership information: Definition of honor society. 2013. http://www.achsnatl.org/membership.asp. (5 June 2013, date last accessed).

[3] Allen IE, Seaman, J. Changing course: Ten years of tracking online education in the United States. 2013. http://www.onlinelearningsurvey.com/reports/changingcourse.pdf. (14 June 2013, date last accessed).

[4] Russell, TL. The no significant difference phenomenon: A comparative research annotated bibliography on technology for distance education. Montgomery, AL: International Distance Education Certification Center, 2001.

[5] Carriuolo, N. The nontraditional undergraduate and distance learning: Is higher education providing a portal or just a keyhole to social and economic mobility? Change. 2002; 34(6): 56. http://dx.doi.org/10.1080/00091380209605570

[6] Miller, MT.,Lu, MY. Serving non-traditional students in e-learning environments: Building successful communities in the virtual campus. Education Media International. 2003. http://www.tandf.co.uk/journals (4 June 2013, date last accessed).

[7] Swan, K, Shea, P. The development of virtual learning communities. In Asynchronous Learning Network: The Research Frontier. SR Hilz and R Goldman, eds. New York: Hampton Press, 2005, 239-260.

[8] American Association of Colleges of Nursing. 2012-2013 Enrollment and graduations in baccalaureate and graduate programs in nursing, 2013. http://www.aacn.nche.edu/downloads/ids/2013/EG12.pdf. (6 June 2013, date last accessed).

[9] Lillibridge, J. Sigma Theta Tau International: Phi Gamma Chapter, 2012. http://phigamma.nursingsociety.org/PhiGammaChapter/Home/ (14 June 2013, date last accessed).

[10] Sigma Theta Tau International (STTI). Determining membership eligibility per STTI bylaws, 2012. http://www.nursingsociety.org/Chapters/StartChapter/Pages/DHSDeterminingMembershipEligibility.aspx (23 July 2013, date last accessed). 